\title{
Como gostaria de ser cuidado na velhice? Opiniões dos Conselheiros Municipais de Saúde da Região Metropolitana de São Paulo.
}

\section{How would you like to be taken care of in old age? Opinions of Municipal Health Counselors of the Metropolitan Region of São Paulo.}

\section{¿Cómo le gustaría ser atendido en la vejez? Opiniones de Consejeros Municipales de Salud de la Región Metropolitana de São Paulo.}

Ruth Gelehrter da Costa LOPES ${ }^{1}$

Bernadete OLIVEIRA

Maria Helena Villas Boas CONCONE

Beltrina CÔRTE

Vicente Paulo ALVES

Otavio NOBREGA

Título abreviado: Opinião dos Conselheiros de Saúde na RMSP

Financiamento: O presente estudo teve apoio financeiro por parte da Fundação de Apoio à Pesquisa do Distrito Federal (processo FAPDF 193.000.354/2010) assim como Ministério da Saúde (processo FNS 25000.191.619/2010-25).

RESUMO: Sabendo-se que a participação da comunidade contribui em nível local para a formulação de estratégias e controle da execução das políticas de saúde, o objetivo deste estudo consistiu em apresentar as opiniões de Conselheiros atuantes na Região Metropolitana de São Paulo (RMSP) sobre como gostariam de ser cuidados em 2030, marco temporal em alusão à própria velhice. Adotamos o método descritivo para interpretação de entrevistas semiestruturadas conduzidas com 39 sujeitos voluntários. Além de revelar o perfil sociodemográfico do Conselheiro de Saúde da RMSP, identificou-se que os entrevistados adotaram, de forma não diretiva, três outras categorias significativas em suas falas além do 'como ser cuidado', a saber: 'por quem', 'onde' e 'quando'. As opiniões colhidas refletem uma carga de idealização

\footnotetext{
1 Professora Associada da Pontifícia Universidade Católica de São Paulo. Tem experiência na área de Saúde Coletiva, com ênfase em Gerontologia e Psicogerontologia. Pontifícia Universidade Católica de São Paulo, Programa de Pós Graduação Em Gerontologia. Rua Ministro de Godói 969 - 4o andar. PERDIZES CEP: 05015-901 - Sao Paulo, SP - Brasil. email: ruthgclopes@pucsp.br
} 
e contraste com o cuidado que se entende ser direcionado pelo SUS ao idoso na atualidade. Palavras-Chave: Conselhos de Saúde. Saúde do Idoso. Pesquisa sobre Serviços de Saúde. Entrevista. Gerontologia.

ABSTRACT: Knowing that community participation contributes at local level to the formulation of strategies and control in the implementation of health policies, the aim of this study was to present the standpoint of Counselors acting in the Metropolitan Region of São Paulo (RMSP) about how they would like to be taken care of in 2030, year adopted in allusion to their own old age. We employed the descriptive method to interpret semi-structured interviews conducted with 39 volunteer subjects. Besides revealing the socio-demographic profile of the RMSP Health Counselors, our study revealed that these respondents have freely adopted three other significant categories in their speeches, in addition to the 'how' to be cared, namely 'by whom', ' where' and 'when'. The views reflect a load of idealization and contrast to the care directed by the Brazilian SUS to the elderly person at present. Key-Words: Health Councils. Health of the Elderly. Health Services Research. Interview. Gerontology.

RESUMEN: Sabiendo la participación de la comunidad a nivel local contribuye a la formulación de estrategias y el control de la ejecución de las políticas de salud, este estudio objetivó analizar el punto de vista de Consejeros de la Salud que actúan en la Región Metropolitana de São Paulo(RMSP), ¿cómo le gustaría ser atendido en el año 2030?, alusión a su propia edad muy avanzada. Adoptamos el método descriptivo para interpretación de las entrevistas semi-estructuradas con 39 sujetos voluntarios. Además de revelar el perfil socio-demográfico de los Consejeros, se encontró que los encuestados han adoptado libremente otras tres categorías en sus discursos, además de la 'cómo ser cuidados', es decir ‘porquié', 'dónde’y ‘cuándo'. Los puntos de vistareflejenunacarga deidealización y contraste con la atención dirigida por el Sistema para las personas mayores en la actualidad. Palavras-chave: Consejos de Salud. Salud del Anciano. Investigación sobre Servicios de Salud. Entrevista. Gerontología.

\section{INTRODUÇÃO}

A Atenção a Saúde do Idoso per se consiste em área relevante por constituir cenário de práticas e experiências que implicam grande produção de conhecimentos sobre o Sistema Único de Saúde (SUS), dado o caráter da universalidade e da integralidade garantidos pelos princípios da Constituição Brasileira ${ }^{1}$. A definição sobre quem cuidará do idoso em um futuro não muito distante apresenta-se como um grande desafio para a gestão pública, especialmente no tocante ao idoso dependente ou que reside só e/ou sem vínculo familiar. Torna-se imperativo neste contexto o conhecimento sobre como, por quem, onde e quando estes cuidados focados no idoso serão realizados. Para compreender este cenário de expectativas e dúvidas - basicamente por ausência de infraestrutura eficiente por parte da Saúde e da Assistência Social, o estudo aqui relatado busca a opinião dos representantes dos Conselhos Municipais de Saúde da Região Metropolitana de São 
Paulo acerca da questão "Como o Sr(a) gostaria de ser cuidado em 2030?"2, fazendo referência a este marco temporal enquanto alusão à própria velhice.

A população mundial atinge contingentes jamais vistos, tendo chegado a 7 bilhões de indivíduos em 2011. Há atualmente 893 milhões de pessoas com mais de 60 anos no mundo. Até a metade deste século, este número (segundo estimativas) deverá praticamente triplicar, chegando a 2,4 bilhões de pessoas ( 1 em cada 4 pessoas com idade $\geq 60$ anos). A estimativa é de que o contingente de idosos ultrapasse 9 bilhões de pessoas até 2050, segundo dados do Fundo de Populações das Nações (UNFPA) da Organização das Nações Unidas ${ }^{2}$. Mesmo em nações ricas, o baixo número de jovens implica incertezas sobre as estruturas sociais e arranjos familiares que cuidarão dos idosos nesta perspectiva de futuro.

As informações apresentadas a seguir podem auxiliar na compreensão da necessidade por estratégias e por estabelecimento de metas para programas específicos direcionados à população que envelhece. Estatísticas descritivas e projeções mostram que o Brasil está envelhecendo, a par da diminuição da fecundidade ocorrida entre 1960 e 2010, e por uma elevação da expectativa de vida ao nascer, que passou de 41 para 73 anos de idade. Assim, nosso contingente de idosos passou de 3 milhões em 1960 para 21,7 milhões em $2010^{3}$. A maior concentração populacional encontra-se no estado de São Paulo. Entre os estados considerados mais “envelhecidos”, São Paulo ocupa a quarta posição, com mais de 5 milhões de idosos. A Região Metropolitana de São Paulo (RMSP), uma agremiação contígua e conurbada de 39 distintos munícipios ao redor da cidadecapital, contava em 2009 com o maior contingente de habitantes do estado: 20 milhões de pessoas (47,8\% da população do estado), das quais cerca de 2 milhões são idosos ${ }^{4}$.

Neste cenário, imaginar um modelo de saúde que atenda a todo o país não é fácil, mas ele já existe e foi definido na Constituição Brasileira: consiste no Sistema Único de Saúde (SUS), por meio do qual a população brasileira, em sua totalidade, deve ter garantidas ações de promoção da saúde, prevenção de doenças, cura e reabilitação ${ }^{1}$. O processo de implantação do SUS exigiu a construção de uma sofisticada engenharia institucional e de gestão para dar conta da complexidade que significa produzir saúde em um contexto de tamanha dispersão territorial e heterogeneidade. A participação da comunidade, por meio da instalação do Conselho Municipal de Saúde (CMS), para formulação de estratégias e controle (inclusive nos aspectos econômicos e financeiros) da execução da política de saúde, também está assegurada pela Constituição e na Lei Orgânica da Saúde ${ }^{5}$. Cada CMS é órgão permanente e deliberativo, e em geral têm composição tripartite, com representantes do segmento gestor (diretores de unidades de saúde) e de profissionais (trabalhadores) de saúde

2 Parte da Pesquisa de Doutorado de Bernadete de Oliveira, no Programa de Estudos Pós-Graduados em Ciências Sociais (PUCSP), intitulada “Quem Cuidará de Nós em 2030? Método Delphi eletrônico para prospecção dos serviços e cuidados de saúde necessários ao idoso da Região Metropolitana de São Paulo”, que ora apresentamos e que se insere neste Projeto de Origem, mas também é complementar a ele no que concerne a sua extensão para todos os municípios da RMSP ( $\mathrm{n}=39$ ) e na identificação dos sujeitos como representantes do Conselho Municipal de Saúde, um (1) do segmento gestor e um (1) outro do segmento usuário, bem como a inclusão de um (1) representante do Conselho Municipal do Idoso. Foi aprovada pelo Comitê de Ética e Pesquisa da Pontifícia Universidade Católica de São Paulo (PUCSP), Protocolo de Pesquisa n ${ }^{\circ}$ 284/2011. 
(25\%), dos prestadores de serviço (25\%) e usuários (50\%). O CMS é de inestimável importância, por ser um fórum participativo nos municípios, como espaço de opinião e de deliberação dos cidadãos nas decisões, principalmente no que se refere a sincronismo entre atuação dos representantes dos segmentos de usuário, trabalhador e gestor do município. ${ }^{3}$

Neste sentido, apreender a percepção e compreensão da realidade (assim como desejos e anseios) desses protagonistas da gestão pública em saúde, é procurar aproximação com o modo pelo qual poderão influenciar o processo político-administrativo que conduz à busca de soluções para atendimento às questões relativas à assistência à saúde das pessoas. A pesquisa com Conselheiros Municipais de Saúde da RMSP, a respeito de como gostariam de ser cuidados em 2030, possibilita a esses representantes refletirem sobre o aprimoramento de ações efetivas nos serviços de saúde para os idosos residentes na região. ${ }^{4} \mathrm{O}$ objetivo deste artigo é apresentar o ponto de vista dos Conselheiros Municipais de Saúde, da RMSP, segmento gestor ou trabalhador, sobre como gostariam de ser cuidados em 2030, através de um instrumento que os convide à reflexão sobre o SUS.

\section{DESENVOLVIMENTO}

A pesquisa de campo foi realizada no período de agosto a dezembro de 2011, com 39 sujeitos de ambos os sexos, atingindo a representação de todos os Conselheiros Municipais de Saúde da RMSP, convidados a participar de uma Entrevista Presencial e Gravada, em local, data e horário por eles estipulados. A adesão ao estudo se deu por voluntariedade de cada sujeito. Cada entrevista seguiu um Questionário Semi-Estruturado, focado sobre a identificação do perfil social, econômico e cultural, em meio a um Roteiro de Entrevista direcionado para colher as iniciativas para a saúde do idoso no respectivo município. A participação foi oficializada por meio de assinatura do Termo de Consentimento Livre e Esclarecida (TCLE) segundo preceitos éticos em pesquisa ${ }^{6}$.

O registro do áudio de gravação, utilizado para colher os depoimentos, permitiu apreender expressões e maior aproximação em relação aos conteúdos subjetivos ${ }^{7}$. As narrativas dos sujeitos foram transcritas na íntegra, procurando resguardar o máximo da originalidade das mesmas, sendo efetuadas correções somente para melhor compreensão pelo leitor.

Para a análise descrita neste artigo, selecionou-se como sujeitos representantes do CMS do segmento gestor ou trabalhador assim como o conteúdo de suas respostas à pergunta: "Como o Sr(a) gostaria de ser cuidado em 2030?”.

Adotamos o método descritivo com abordagem qualitativa para interpretação de opiniões, visando compreender a complexidade dos temas - envelhecimento e cuidar. Para tanto, compartilhamos os

3 O CMS é composto por usuários, profissionais de saúde, gestores e prestadores de serviço, e representa na prática, uma das instâncias do controle social na saúde (BRASIL, 2002).

4 Os Conselheiros atuam no Departamento Regional de Saúde 1 (DRS1): Grande São Paulo, da RMSP, segundo dados do site www.observasaude.sp, concebido conforme o Decreto número: 51.433, de 28 de dezembro de 2.006, constituído por sete Regiões de Saúde (Alto do Tietê, Grande ABC, Guarulhos, Franco da Rocha, Rota dos Bandeirantes, Mananciais, São Paulo) e seus respectivos 39 municípios. 
desafios de Laplantine ${ }^{8}$ : Como ordenar, ou seja, pensar essa abundância de elementos? Como, por trás de tal diversidade, identificar as tendências principais? Como discernir atitudes que, se não são idênticas, são, pelo menos, cruzadas por linhas de forças comuns? E após a identificação dessas tendências, como pensá-las em relação umas às outras? Ademais, Chizzotti (2003) apresenta a fundamentação teórica segundo a qual a abordagem qualitativa - aqui adotada - parte do fundamento de que existe uma relação dinâmica e interdependente entre os sujeitos (investigador e participante), ou seja, um vínculo entre o mundo real e a subjetividade ${ }^{9}$. Constrói-se assim um espaço no qual o sujeito-observador faz parte do processo de conhecimento e interpreta os fenômenos, atribuindo-lhes significado ${ }^{10}$. A questão investigada não é um dado inerte e neutro; está entranhada de significados e relações que sujeitos concretos criam em suas ações. Sendo assim, os envolvidos elaboram conhecimentos e produzem práticas no cotidiano enquanto Representantes do Conselho Municipal de Saúde ${ }^{9}$.

Outro referencial teórico adotado, desenvolvido por Geertz, permite uma aproximação com o objeto deste estudo, não por explicações definitivas, mas como uma interpretação social e cultural entre outras, que poderão surgir ${ }^{11}$. A ideia não é captar uma única verdade, e sim propiciar mais uma leitura para o fenômeno aqui estudado: o envelhecimento e o cuidado. Nas falas dos depoentes, colhemos interpretações subjetivas, negando a naturalização das explicações aparentes e buscando o cerne do pensamento e/ou sentimento em face da problemática estudada.

\section{RESULTADOS}

Para apresentar o perfil social, econômico e cultural dos sujeitos entrevistados, descrevemos as características globais: 21 (53,8\%) homens e 18 (46,2\%), mulheres; 21 (53,8\%) encontravamse casados ou em união estável, enquanto 12 (30,8\%) eram solteiros e $6(15,4 \%)$, separados ou divorciados; a maioria $(\mathrm{n}=33 ; 85,0 \%)$ relatou ter cursado ensino superior completo (média $\geq 15$ anos de estudo). A idade mínima foi de 28 anos, e máxima de 66 anos (média = 44,6 $\pm 10,3$ anos). Apenas uma minoria $(n=6 ; 15,4 \%)$ relatou morar só (média de residentes no domicílio $=3 \pm 1$ ). A amplitude da renda familiar variou entre $\mathrm{R} \$ 700,00$ e $\mathrm{R} \$ 30.000,00$ (renda média $\mathrm{R} \$ 7.460,00 \pm$ $5.400,00) .^{5}$

A maioria apresentava escolaridade com formação superior, com preponderância e m cursos da área de Saúde, a saber: 7 (17,9\%) em Enfermagem, 5 (12,7\%) em Medicina, 3 (7,7\%) em Odontologia; 2 (5,1\%) em Farmácia, 2 (5,1\%) em Pedagogia, 2 (5,1\%) em Direito, 2 (5,1\%) em Administração, 2 (5,1\%) em Magistério, 1 (2,6\%) em Psicologia, 1 (2,6\%) em Educação Física, 1 (2,6\%) em Biomedicina, 1 (2,6\%) em Biologia, 1 (2,6\%) em Relações Públicas, 1 (2,6\%) em Serviço Social, 1 (2,6\%) em Gestão do SUS e 1 (2,6\%) em Recursos Humanos. Apenas 2 (5,1\%) Conselheiros não informaram sua área de formação, enquanto $4(10,3 \%)$ declararam não ter formação superior.

5 O valor do salário mínimo em 2011 era de R \$ 545,00. Disponível em: <www.guiatrabalhista.com.br/guia/ salario_minimo.htm> Acesso em: 02 de fevereiro de 2012. 
Vinte e nove dos sujeitos entrevistados eram provenientes do segmento gestor. Dentre aqueles que declaram exercer posição de direção em meio à estrutura organizativa interna do Conselho, 8 declararam exercer a Presidência do Conselho, 3 declararam a Vice-Presidência, 3 exerciam o papel Secretário(a) enquanto 1 declarou ser Fiscalizador da Saúde. Os demais 14 Conselheiros entrevistados não souberam definir ou não declararam exercer função de direção no Conselho. Quanto aos demais Conselheiros entrevistados $(n=10)$, pertencentes ao segmento trabalhador, 5 não souberam ou não declararam exercer função de direção, enquanto 1 exercia a Presidência, 1 a Vice-Presidência, 2 o papel de Secretário(a) e 1 a função de Articulador. Destacamos ainda que dos 29 Conselheiros do segmento gestor, 7 (24,1\%) eram os próprios Secretários Municipais de Saúde.

Ressaltamos ainda que, em 2030, os depoentes terão em média 63,7 $\pm 10,4$ anos de idade, sendo a idade mínima sendo igual a 47 anos e a máxima, 85 anos.

A interpretação das falas dos sujeitos

Foi possível perceber que os Conselheiros Municipais de Saúde imaginam os desafios do envelhecimento humano (velhice) por meio de uma articulação, resgate ou idealização com eventos pregressos (passado) de vivência pessoal ou familiar e/ou exemplos de experiências vivenciadas por outrem, ou ainda partindo de uma reflexão sobre os serviços de saúde dispensados hoje (presente) por uma rede que administram, projetando para o futuro as expectativas de melhoria ou aperfeiçoamento destes serviços. Ademais, percebeu-se que os entrevistados indicaram, de forma não diretiva, três outras categorias significativas em seus relatos, para além do COMO ser tratado, a saber: POR QUEM, ONDE e QUANDO.

Dentre as respostas dos representantes do segmento gestor ou trabalhador à questão "Como o Sr(a) gostaria de ser cuidado em 2030?", acerca de COMO essas pessoas imaginam ser cuidadas na própria velhice, os resultados apontam para respostas preponderantes que conjugam expectativa ("com atenção") e receio e/ou temor ("sem que me transformem em objeto"). Abaixo as respostas:

...sem que ninguém me dê ordem, mas que me dê apoio e ajuda, mas que não me transforme em um objeto.

...mais médico para idoso, mais acesso para o idoso e mais liberdade. Porque quando você fica mais idoso, dependendo de onde mora, você fica trancada, porque você não tem como sair mesmo de casa.

Com acesso, o idoso não pode chegar e ouvir: olha o senhor não tem nada, o problema do senhor é a idade, acho que o idoso tem que ter acesso ao serviço da saúde.

Quero ser cuidado com harmonia.

...eu gostaria de ter um atendimento humanizado. 
...com atenção mesmo.

...com atenção

Bem cuidado. Com atenção, carinho, paciência, e que saiba ouvir.

....atenção é tudo.

...com respeito e dignidade, que é o mínimo.

...ser respeitado como idoso.

...com respeito, dedicação, bem acolhida.

...bem acolhido. Ser ouvido, respeitado, acho que isso é o principal. É a prioridade.

...uma idosa com autonomia, sem muitos problemas de saúde, e que o serviço público me dê tudo aquilo que eu necessitar e com qualidade, com respeito.

Com respeito, me considerando cidadão como as outras faixas etárias, e com acesso gratuito à Saúde.

...primeiro com simplicidade, depois igualdade e liberdade, principalmente. ...ser ouvido (...) como membro inserido da comunidade.

...fazendo alguma atividade, de alguma ação voluntária...

...que me tratassem como uma pessoa com mais experiência de vida, não só como idosa.

...como aquele senhor que estava na cadeira de rodas, a gente percebia pela vestimenta dele, que ele estava de fradas, fazendo fisioterapia e sendo recebido com um beijo pela coordenadora.

Em 2030, eu gostaria de ter acesso na minha área de abrangência, eu gostaria de participar de todo esse movimento, estar fazendo minha atividade da $3^{a}$ idade por aqui, estar aposentada, mas curtindo a vida e ser útil, por exemplo, eu poderia ser voluntária num hospital com todo meu conhecimento...

Eu gostaria de envelhecer consciente, mas se acontecer alguma coisa, gostaria de ter alguém a meu lado. Não só a família basta, você tem que ter uma orientação de um profissional.

Paparicada (...) eu quero estar pensando, elaborando projetos, com jovens, velhos, eu quero estar inserida socialmente, quero para mim e para os outros. Quero continuar fazendo parte da sociedade.

Em síntese, observa-se que a "coisificação" do indivíduo em meio à "linha de produção" do sistema de saúde prevalece como preocupação constante, suscitando que seja efetivada a prática da humanização da atenção à pessoa idosa, conforme preconizado em políticas públicas. 
No quesito POR QUEM, destaca-se uma polarização: ora esperam ser cuidados por familiares, ora por bons profissionais de saúde, ou mais frequentemente por ambos. Em regra, não dispensam os cuidados ou a presença de familiares em seu convívio, mas destacam a necessidade da presença de profissionais qualificados ao mencionarem a expectativa de atendimento por parte da rede de saúde, especialmente ante a possibilidade do advento da dependência/incapacidade física. Abaixo, as principais transcrições:

...eu gostaria que o SUS cuidasse de mim.

...por esse pessoal com que eu trabalho.

...o profissional está te atendendo com simpatia, com cuidado, com empatia, não simplesmente que eu fosse mais uma idosa, mais um número na produção.

...profissional que tem esse respeito pela vida.

...atendimento qualificado com uma atenção especial.

...se eu precisasse de uma unidade básica de saúde, que tivesse profissionais capacitados para melhor resolver os problemas da geriatria.

Pela minha família, mas também com a ajuda de profissionais capacitados. ...que se interessam pelo que estão fazendo, eu acho que a base de tudo é o interesse pelo ser humano.

Eu espero que meus filhos cuidem de mim como eu pretendo cuidar dos meus pais e dos meus avós hoje.

Eu queria sentir o carinho da minha família, não quero ser colocada em asilo para não dar trabalho.

...minha familia vai ter uma participação maior, porque já é o costume, tive minha avó, que a família cuidou, minha mãe, e meus filhos têm que cuidar de mim.

Percebe-se pelas opiniões expostas o desejo por se contar com um cuidado protagonizado por profissionais com qualificação gerontológica associada à humanização que se espera conforme relatado anteriormente.

No tocante a ONDE serem cuidados, percebe-se entre os discursos a centralização em torno da franca preferência pelos cuidados em domiciliares ou em unidades de saúde (ou ambos) de bom acolhimento em detrimento (ou com explicita rejeição) pelos cuidados prestados em ambientes institucionais de longa permanência. Nesse caso, a institucionalização não é descartada, mas também não é desejada. A família idealizada ("completa") é vista como garantia de cuidado ou estabilidade "emocional". Faz-se referência ao cuidado de saúde "especial" ou "profissional", 
mas em nenhum momento há referência à iniciativa de qualificação (cursos) para aperfeiçoar o atendimento aos idosos.

Em asilo, não. Eu não quero ir para uma casa de idoso. Queria ser cuidado pela família.

Na família, como já é de hábito na minha família, como eu cuido dos meus avozinhos.

Em casa, gostaria que minhas filhas tivessem cuidado comigo como tive com minha avó. Eu gostaria de estar em casa e se não fosse possivel, no hospital ser cuidada com pessoas que tivessem carinho e cuidados.

...em casa, com a família, mas se eu tivesse uma assistência especializada seria bom.

...em comunidade, cada um ter seus aposentos, não muita coisa, com comodidade, e com áreas em comum, como se fosse um centro mesmo que as pessoas possam conviver.

...alguns lugares para fazer exercícios, grupos para idosos, centros desportivos para idosos.

...cada limitação, você vai desejar que tenha alguma coisa para suprir isso. Se tiver dificuldade para subir escadas, quer que o local tenha acessibilidade. Se você tem problema visual, quer que tenha uma sinalização, que tenha acessibilidade. Se você for um acamado, vai querer um atendimento domiciliar. Se ficar em plena função, vai querer que tenha um centro, um local que você possa compartilhar a vida com outros idosos com atividades físicas, em palestras, que você veja em tudo uma sementinha.

...em serviço de saúde, que seja bom.

...ter um centro especializado, não ter que ficar batendo cabeça para atendimento. Ter um lugar especifico para me cuidar, com pessoas capacitadas para me atender, com carinho pelo que fazem.

Eu vejo com naturalidade isso. Lógico a gente tem de trabalhar para que o número maior de pessoas seja independente até o finalzinho de sua vida, na medida do possível, ser autosustentável, mas a gente não escolhe as doenças, o futuro de nossa vida, temos que trabalhar muito a prevenção, mas sem problema nenhum. Pois é, sou solteiro. Vou casar o ano que vem e ai vamos ver quem vai cuidar de quem... Eu não sei como vai estar o Brasil em 2030, vejo uma mudança muito grande. Nós temos dois tipos de cuidado na realidade. O cuidado de saúde, que requer o cuidado médico, especializado de enfermeira, agora, o cuidado emocional que é o familiar, esperamos que nossa família esteja completa... Nos Estados Unidos é muito comum as casas asilares, eu não sei será legal, eu preferiria ficar no seio da família, eles cuidando de mim lógico se não precisar de um cuidado especial, mas se precisar que eles tenham acesso, para que eu, dentro da possibilidade, fique dentro da família. 
O relato centrado no modelo ideal de "casa" ou "comunidade" embute o pressuposto de família tradicional. No entanto, os novos arranjos familiares associados à baixa fecundidade da população brasileira e inserção da mulher no mercado de trabalho suscitam a preocupação de que o referido modelo encontre-se obsoleto e, portanto, incapaz de atender às expectativas dos entrevistados. A despeito de serem atores de um sistema público voltado a prestar seguridade ao cidadão, destacase a ausência de falas sobre o protagonismo do próprio serviço pelo qual respondem em albergá-lo em sua velhice.

O TEMPO (QUANDO) é considerado uma categoria significativa para os sujeitos, uma vez que o processo de envelhecimento associa-se à questão do decurso temporal. O passado denuncia a perspectiva do discurso (real ou idealizado) de adequação na atenção e respeito ao idoso e na referência a situações de "família exemplar". A temática do TEMPO suscita o aval dos direitos humanos e civis do idoso, quando reflete a necessidade de reconhecimento de uma contribuição social, um legado pelos deveres realizados. Foi possível verificar que há expectativa pessoal, positiva, baseada na referência indireta de que tudo o que falta hoje deverá haver no futuro. Assim se expressam nossos interlocutores, para que o cuidar seja humanizado, uma satisfação ou um sonho realizado:

\section{Eu vou falar humanizada com certeza!}

Todos têm que estar capacitados em 2030, (...) devem estar preparados para receber o idoso. (...) daí, eu vou me dar por satisfeita.

É o meu sonho. (...) entrar num centro de saúde ou centro de idoso e perceber que aqueles profissionais têm capacidade de cuidar daquele grupo com a atenção social também.

Percebe-se, pelas opiniões colhidas, uma referência temporal que remonta ao envelhecimento como evento remoto, quando em verdade o horizonte temporal proposto para reflexão sobre sua velhice (2030) não está tão distante, considerado o momento da redação deste trabalho.

\section{Interpretações Peculiares}

Depreende-se das interpretações que a reflexão realizada, com base nas perspectivas pessoais, indica que, hoje (presente), o cuidar é diferente do que o sujeito gostaria; que a situação pode se inverter (passar de funcionário para usuário da atenção à saúde que ora personifica); e que é premente a necessidade por pessoas éticas e comprometidas em oferecer cuidados, especialmente na esfera pública da qual faz parte e contribui para que o futuro seja "diferente".

Eu gostaria de ser ouvida, de poder falar, que seja com alegria. As pessoas trabalhando, fazendo aquilo que elas gostam de fazer para que eu seja bem acolhida. Se elas estiverem felizes, espero que as pessoas estejam se realizando em seu trabalho, com certeza elas vão fazer aquilo com prazer, com paciência. Que me ofertem mais do que estou pedindo (...) que sejam uma luz por que eu posso chegar lá muito bem, lúcida, como eu posso chegar lá com // Tempus, actas de saúde colet, Brasília, 8(3), 109-123, set, 2014. 
Alzheimer, por exemplo. Que tenha pessoas éticas, pessoas comprometidas, é isso que eu espero encontrar. (...) Que as universidades cumpram seu papel, de formar profissionais de nível superior ou que as milhares de escolas de esquina que formam auxiliar de enfermagem e administradores, tenham essa consciência também, que formem pessoas capacitadas. Que recebam periodicamente novas informações para poder lidar comigo na velhice, espero não dependente. Fazendo a conta, estou com 51 anos, daqui vinte anos eu vou para 71 anos, eu espero estar mais ativa do que nunca, meu corpo pode não responder, mas eu espero estar lúcida para dizer: trabalhei na saúde, fiz parte disso, o tempo que eu passei lá eu tentei me dedicar para que esse momento fosse diferente para mim e para os outros.

Essa perspectiva também pode indicar desejo de fruição, acesso ao lazer, além da garantia de condições para atender às necessidades básicas com qualidade de vida e dignidade. Destacamos os recortes das narrativas que trazem o passado como elemento positivo, para o reconhecimento do idoso como sujeito que tem histórico de contribuição (já trabalhou e deve usufruir) assim como exemplos de apoio familiar, recorrentes nos seguintes recortes:

Se eu pudesse chegar até lá, eu queria estar bem cuidado (...). Passeando muito, viajando muito. ... o idoso trabalhou muito (...) e ele não tem hoje nem o direito (garantido)... Tem uma pessoa ai pedindo para eu ajudar ele se aposentar..

(...) Ele já contribuiu para a família, para a cidade, e está na hora dele usufruir dessa dedicação.

(...) Meus avós foram muito bem cuidados por nós, uma paixão. Eu montei uma enfermaria. Minha avó falava assim: só não quero que você me deixe morrer em um hospital. De jeito nenhum. Na noite que morreu, ela era muito vaidosa, estava com diarréia, ela pediu para levantar, pediu para tomar banho, passou hidratante no corpo todo, inclusive no rosto e morreu dormindo, com dignidade. Ela fez tudo que quis se despediu, com dignidade. Nós não nascemos e vivemos com dignidade? Nós queremos morrer também com dignidade... Porque ele contribuiu para uma sociedade, participou, foi ativo, construiu uma família, é um ser humano, tem uma historia de vida dele e na família, como você não vai dar respeito para ele? Como se descarta uma pessoa que fez história?

Quando à possibilidade de apresentar dependência física na velhice (possibilidade concebida pelos depoentes com certo grau de relutância), as narrativas apresentam o respeito como 'palavra de ordem', fundamental para qualificar o cuidado que esperam receber.

Não, não penso dependente, não consigo imaginar, mas acho que é uma coisa que vai acontecer. Hoje, nós somos completamente ativos, e sei que devemos ter o respeito para romper paradigmas, por isso falo em respeito, temos que saber que isso pode acontecer com a gente lá para frente. Claro, eu acho que nós contribuímos ninguém faz favor em cuidar. Hoje, eu estou como secretário adjunto de saúde, estar como secretário, qual minha obrigação? É cuidar de todo mundo que precisa. Eu posso precisar. 
A tripla referência aos tempos futuro, passado e presente mostra uma articulação discursiva peculiar. Ter dinheiro para preservar a autonomia constitui crença disseminada nos depoimentos (garantia de um futuro a partir de condições pessoais, o que pode sugerir descrença no próprio Sistema de Saúde do qual é parte integrante). Ter saúde como os avós, receber cuidados da família, morrer com dignidade (expectativa calcada nas experiências familiares vividas no passado imediato ou distante) são expressões recorrentes. Quanto ao presente, o discurso articula expectativas pessoais e vivências no atendimento do SUS. Reconhecem-se necessidades: cuidador capacitado e/ ou cuidado profissionalizado. Aponta-se o ideal e os direitos de cidadania; o cuidador é bem vindo, desde que atento às demandas subjetivas e de atividades de vida diária do velho. Sugerem-se assim alternativas aos cuidados familiares, onde relata-se a perspectiva de viver em espaços residenciais coletivos, desde que qualificados.

Eu estou pensando muito nisso. (...) Eu quero ser independente... Assim como meus avós foram... Ter dinheiro, porque não posso acreditar que vou ser bem cuidada nessa saúde pública que vivo e que faço a gestão hoje. Como eu não tenho filhos, eu penso muito nisso. Ter bons amigos, relacionamentos e uma família boa. Não quero ser cuidada como uma demente. Como uma velhinha qualquer. Quero passear e na hora que não der mais, tenho que ter condições financeiras para fazer o que eu quero no meu tempo... Que em minha velhice, peço a Deus, que não tenha nenhuma doença maior (...) que eu possa ser como meus avós: receba o mesmo respeito que nós tivemos por eles... Se eu for incomodar a família, que possa ir para um lugar e que eles venham me visitar. Mas não penso num asilo. Eu penso nessas novas propostas que existem para o idoso. Tem que profissionalizar esse cuidador. Tem que valorizar essa pessoa, porque sem eles vai ficar difícil. Muitas vezes não precisam de um enfermeiro, mas de um cuidador.

A despeito da função e/ou cargo públicos que os sujeitos entrevistados ocupam, ressalta-se que as falas não trazem muitas referências a ações para mudar o panorama atual de atenção à saúde da pessoa idosa, ou para atingir metas na dimensão pública (exemplo: quero a qualificação de servidores ou a formação de cuidadores) - apenas na pessoa (quero ser exemplo para meus filhos). Preconiza-se que este modelo seja reproduzido socialmente. Ao mesmo tempo, várias falas assinalam a indissociabilidade do compromisso entre Estado e Sociedade no cuidado do idoso, neste tempo ou no futuro, sem especificar a estrutura da rede de apoio. A institucionalização do idoso é enfaticamente descartada.

Primeiro de tudo com atenção. É essencial. Tem gente que faz que ouve o idoso mas não ouve. Depois, ser valorizado pelo meu conhecimento e contribuições, pequenas, mas que foram dadas... Eu sou totalmente contrário a instituições asilares que cuidam de idosos. A família tem um compromisso com seu próprio passado em preservar e cuidar de seus idosos com suporte do estado, mas a família tem que contribuir, não só o estado, não é só o estado provedor, a família e a sociedade têm suas obrigações... Que eu tenha um sistema de saúde que me ajude a cuidar das doenças que tenho e prevenir outras, e também me ajude a me manter um idoso ativo, 
e também um sistema educacional que pense no idoso. Que o idoso sempre descubra coisas novas, sempre aprenda coisas novas, mas o principal é a atenção. (...) Eu quero ser cuidado pela família. É muito fácil você achar que não consegue cuidar do idoso e mandar para uma instituição, mas é isso que você quer para o futuro? Que alguém faça isso com você? Eu, por exemplo, cuido da minha sogra e meus pais. Quero ser um exemplo para meus filhos. Essa é minha meta, que eles sejam assim comigo.

Nossas interpretações podem ser relevantes para se pensar o funcionamento dinâmico e integrado do Sistema Único de Saúde brasileiro, tomando-se as impressões, os anseios, as expectativas e os temores de protagonistas da construção com participação social das decisões locais em saúde como ponto de partida para a operacionalização de uma rede de apoio social para permitir ao idoso o acesso ágil, eficaz e eficiente - conforme necessário e desejado.

\section{CONSIDERAÇÕES FINAIS}

Como síntese para as respostas obtidas, são mencionados explicitamente pessoas da família como bons cuidadores, e o domicílio (ou ambientes com os quais se identifica) como os mais desejáveis, remetendo a fatos acontecidos no passado. No entanto, grande referência (ou ênfase) é dada à consideração e ao respeito com os quais desejariam ser tratados na velhice, pela contribuição social dada ao longo da vida. Em termos pessoais, depreende-se das falas dos sujeitos uma excessiva valorização da família como depositária das qualidades necessárias ao cuidado: a família deve ser a cuidadora com o apoio de ações e serviços do Estado. Em termos gerais, valorizam o conhecimento e insistem na necessidade de se garantir escuta e dedicação. A ressaltada necessidade por respeito e escuta (há paralelismo entre estes temas) pode ser interpretada como reconhecimento de falta generalizada destas qualidades no 'ato de cuidar' hoje. Mas não há indicação de planejamento para profissionalizar este cuidado (qualificado, desejado e necessário) tanto no espaço privado quanto no público.

O presente é exaustivamente repassado como exemplo de como não deve ser o futuro. Constatamos aqui um perigoso vácuo. Ao futuro, são atribuídos termos com forte carga de idealização: liberdade, sonho, satisfação, igualdade, fruição, respeito, independência, humanização, atenção e escuta. Ao passado, o incontestável amparo familiar, sempre lembrado como positivo. E no presente, os sujeitos que poderiam atuar viabilizando parte dessas expectativas parecem não se sentir responsáveis e/ ou não se vêem com poder de intervenção na estrutura e dinâmica político-administrativa do qual participam, a despeito da função social que executam. Para usar o antônimo de um neologismo contemporâneo, parece haver um "desempoderamento" dos gestores diante da complexa tarefa e do tamanho da máquina burocrática do Sistema Único de Saúde brasileiro e do paradigma que o governa, centrando no modelo biomédico de atenção à saúde.

As opiniões dos interlocutores dão vida ao dia-a-dia do servidor público que trabalha e/ou administra o SUS (como dissemos no início), passando do idealizado ao "duro chão" da realidade. 
Traz o cenário do cuidado universal garantido pelos princípios da Constituição Brasileira para o palco do cotidiano e seus imponderáveis. Espera-se com esta pesquisa buscar o relacionamento entre o cenário (emoldurado pelos princípios das políticas públicas) e o cotidiano (vivenciado pela subjetividade das experiências pessoais) pela escuta dos atores que ora são protagonistas idealizadores e operadores na construção do sistema público de saúde brasileiro. Espera-se ainda alimentar o olhar crítico e ajudar na identificação dos caminhos para a atenção integral que se almeja, o que representa um avanço para a atuação desses servidores públicos que poderão, com maior propriedade, zelar pela Saúde no país. Afinal, a problemática dos cuidados necessários, das demandas por atendimento especializado e das dificuldades no acesso aos cuidados ora dispensados pelo SUS são desafios constantes para articulação e implementação das estratégias e políticas almejadas para este segmento social.

\section{REFERÊNCIAS BIBLIOGRÁFICAS}

1. Brasil. Constituição da República Federativa do Brasil. Brasília - DF: Senado Federal; 1988.

2. Situação da População Mundial. Organização das Nações Unidas, 2011. (Accessed $1^{\circ}$ de novembro de 2011, 2011, at http://www.bbc.co.uk/portuguese/noticias/2011/10/111025_onu_ populacao_jovens_mdb.shtml.)

3. Sinopse do Senso Demográfico de 2010. Instituto Brasileiro de Geografia e Estatística, 2011. (Accessed 16 de dezembro de 2011, at http://www.ibge.gov.br/home/estatistica/populacao/ censo2010/default_sinopse.shtm.)

4. Síntese de Indicadores Sociais - Uma Análise das Condições de Vida da População Brasileira. Instituto Brasileiro de Geografia e Estatística, 2008. (Accessed 02 de dezembro de 2011, at http://www.ibge.gov.br/home/estatistica/populacao/condicaodevida/indicadoresminimos/ sinteseindicsociais2008/indic_sociais2008.pdf.)

5. Brasil. Guia do conselheiro: curso de capacitação de conselheiros estaduais e municipais de saúde. Brasília - DF: Ministério da Saúde; 2002.

6. Concone MH, Cerveny CM. Research and the (free and) informed consent. Cien Saude Colet 2008; 13:341-9.

7. Thompson P. A voz do passado: história oral Rio de Janeiro: Paz e Terra; 1992.

8. Laplantine F. Antropologia da Doença. São Paulo: Martins Fontes; 1991.

9. Chizzotti A. Pesquisa em Ciências Humanas e Sociais. $6^{\text {a }}$ edição ed. São Paulo: Cortez; 2003.

10. Minayo MCS. O desafio do conhecimento - Pesquisa qualitativa em saúde. São Paulo: // Tempus, actas de saúde colet, Brasília, 8(3), 109-123, set, 2014.

ISSN 1982-8829 
Hucitec/Abrasco; 2000.

11. Geertz C. A interpretação das culturas. Rio de Janeiro: Zahar; 1989.

Artigo apresentado em 04/04/14

Artigo aprovado em 08/08/14

Artigo publicado no sistema em 12/09/14 